(ISSN:2576-3989)
(IS)

\title{
A Mathematical Model for Analyzing the Impact of the Ban on Foreign Garbage in China
}

\author{
Jiaying Yan $^{1 *}$, Gaozhen $\mathrm{Ni}^{1}$ \\ ${ }^{1}$ College of Electrical Engineering \& New Energy, China Three Gorges University, Yichang, 443002, \\ China.
}

\begin{abstract}
Focusing on the issue of the ban on foreign garbage, this paper analyzes the impact of the ban on China from both qualitative and quantitative perspectives. By collecting before and after the trash ban of China, China's imports of scrap metal, waste paper, waste plastics data and related producer price index. it is concluded by granger causality test model that under the $5 \%$ confidence interval, the waste imports less, the higher the related product producer price index; Secondly, based on nemero pollution evaluation model, this paper finds that the nemero score of water quality in China has decreased by 0.026 and the water quality has improved to some extent. The two models established in this paper are of great significance for analyzing the impact of the ban on foreign garbage on China and specifying corresponding measures
\end{abstract}

Keywords: Foreign garbage ban; Granger causality test; Nemero pollution evaluation
*Correspondence to Author:

Jiaying Yan

College of Electrical Engineering \& New Energy, China Three Gorges University, Yichang, 443002, China.

How to cite this article:

Jiaying Yan, Gaozhen Ni. A Mathematical Model for Analyzing the Impact of the Ban on Foreign Garbage in China. Research Journal of Mathematics and Computer Science, 2020; 4:18

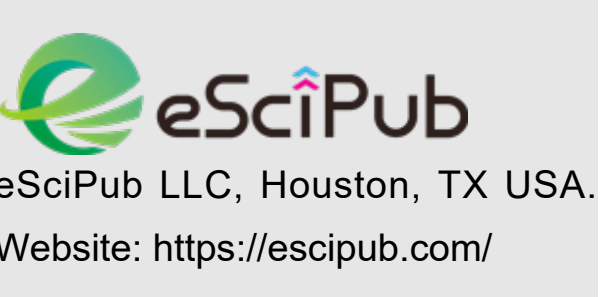




\section{Introduction}

China is the world's largest importer of waste, importing more than half of the global trade each year. More than three-quarters of China's imports of solid waste are waste paper and plastic, mainly from the United States, Japan and the United Kingdom and other developed countries. In July 2017, China officially issued a ban on the import of 24 types of solid waste from the world, including four types of highly polluting solid waste, waste plastics from living sources, vanadium slag, unsorted paper and waste textile materials. ${ }^{[1]}$ In April 2018, the ministry of ecology and environment issued a notice on the revision of the management catalogue of imported waste, deciding to change 32 types of solid waste, including waste hardware, waste ships and waste automobile pressing parts, from "limited import" and "non-limited import" to "prohibited import". At the end of 2018, the ministry of ecology and environment announced that it would gradually reduce imports of solid waste, known as "foreign waste". ${ }^{2]}$ Before the end of 2019, "foreign garbage" will be completely banned from entering China. After part of the ban came into effect, a large-scale reorganization of the global garbage industry chain was initiated, which undoubtedly had a certain impact on China and even the world. Based on this, the problem to be solved in this paper lies in the analysis of the issue of foreign garbage ban on China's economy and environment will produce what kind of impact. ${ }^{[3]}$

\section{Model hypothesis and symbol description}

\subsection{Model hypothesis}

Hypothesis1: the data collected from each channel is true.

Hypothesis2: the changes of national economy and environment are only restricted by the foreign garbage factors considered in this paper. Hypothesis3: the concentration of pollution factors is not considered in the national wastewater discharge.

\section{2 symbol description}
symbol
symbol description

\begin{tabular}{c}
$X \quad$ Import volume of foreign garbage \\
$Y \quad$ The standard values of the monitoring indicators in category I water quality \\
$L_{i 1} \quad$ the maximum standard limits for category I water quality \\
$l_{\max } \quad$ The category of test items corresponding to the maximum concentration \\
$C_{i \max }$ \\
\hline
\end{tabular}

\section{Problem analysis}

Based on the problem of how the ban of foreign

garbage will affect China's economy and environment, this paper intends to use mathema- 
tical model to explain and analyze. As for the economic impact, considering that the change of one variable in economics may have complicated relations with multiple variables, this paper intends to use the granger causality test model to judge whether the ban on "foreign garbage", namely the ban on the import of waste paper, waste plastic and waste metal, will have an impact on China's economy. As for the environmental impact, from the three aspects of water source, soil and atmosphere, this paper adopts the Nemero comprehensive pollution evaluation model to quantitatively study the water pollution level in the years before and after China's ban on foreign garbage. By comparing the environmental pollution before and after the ban, this paper illustrates the impact of the ban on China's environment. The flow chart of specific ideas is shown in figure 1 below:

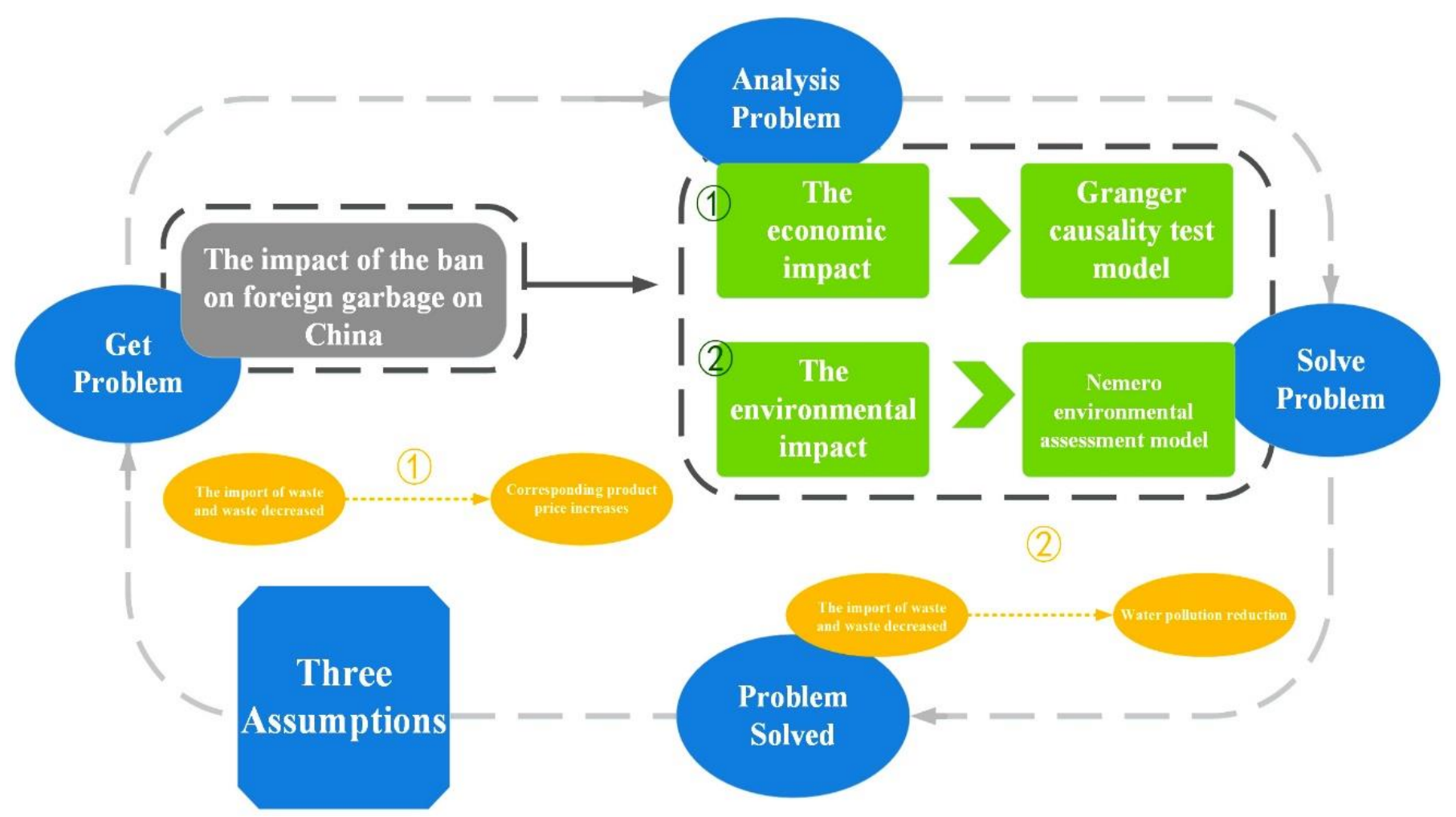

Fig 1 flow chart of full text idea

\section{Data collection and analysis}

\subsection{Analysis on the quantity of waste paper imported and its price index}

Explanation: producer price index (PPI) is a relative number reflecting the trend and degree of change of the total level of producer price of all industrial products in a certain period, including all kinds of products sold by industrial enterprises to all units other than their own enter- prises and products sold directly to residents for living consumption. This index can observe the impact of changes in factory gate prices on total industrial output and value added.

The import quantity of waste paper and garbage collected on the Internet from 2017 to 2019 and the producer price index of papermaking and paper products are shown in Fig. 2: 


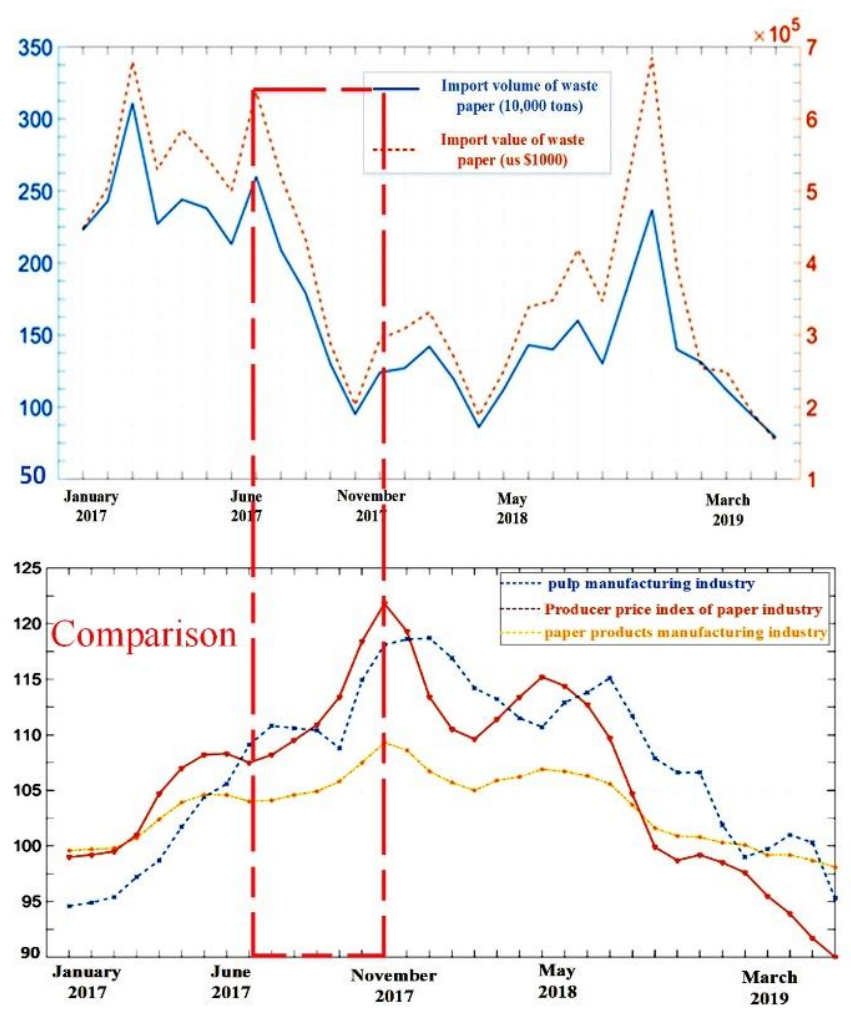

Fig 2 comparison of waste paper import volume and price index of paper products

By comparing the above we can see, in July 2017 China officially issued a ban on "foreign garbage" to the world, after a sharp drop in imports of waste paper, the reduce of raw material has led to the higher price of domestic paper products and increased the economic burden of related companies. After few months, China took measures to adjust domestic waste paper recycling, then waste paper imports to maintain downward trend and fluctuation within a certain scope, at the same time, the price of paper is reduced, which shows that after adjustment of domestic paper products industry, it can adapt to the impact of the "foreign garbage" ban.

\subsection{Analysis of the quantity of waste plastic} imported and its price index

The import quantity of waste plastic waste in China from 2017 to 2019 and the producer price index of plastic products industry collected on the Internet are shown in the following trend chart, as shown in figure 3 :

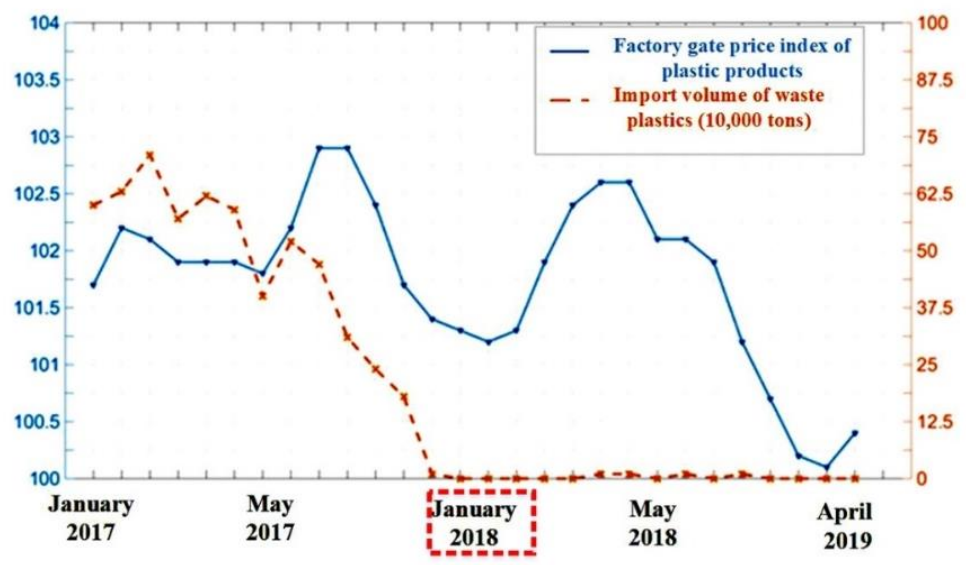


Fig 3 comparison of import volume of waste plastics and price index of plastic products

As can be seen from the figure above, in January 2018 , the import volume of waste plastics in China was effectively controlled. The import volume of waste plastics was only 10,000 tons or none at all, and was effectively controlled for several months after that. The PPI of the plastics industry fluctuated little before and after the ban, but eventually showed a downward trend, suggesting that China may have adapted to the ban by 2019 .

\subsection{Analysis of scrap metal import quantity and its price index}

The import volume of China's scrap metal waste collected online and the producer price index of the metal products industry in 2017 are shown in figure 4:

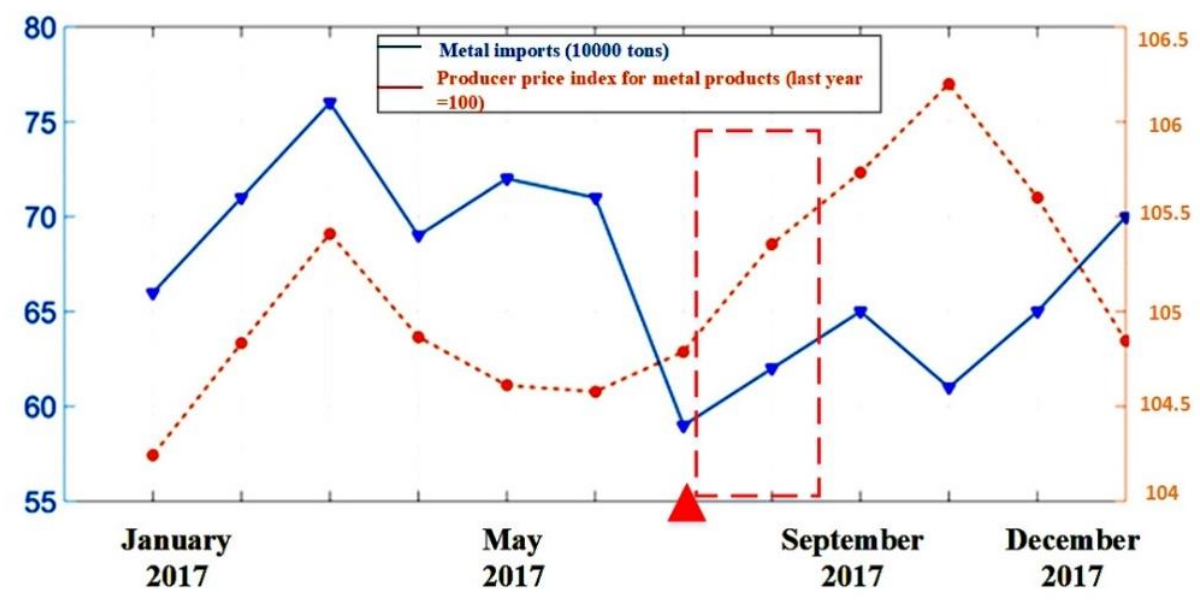

Fig 4 comparison of china scrap metal import volume and metal products price index

By above can see, in July 2017, China officially released after the trash ban, have a certain effect, scrap metal imports fell, the reversed transmission fabricated metal products producer price index rose, guess scrap metal imports has relationship with metal products price index, the garbage ban would lead to metal products prices rise.

\section{5 . Establishment of granger causality test model}

\section{Step1: Data Detrending}

Considering that granger causality requires the time series to be stationary, the original data must be de-trending.

\section{Step2: Remove The Mean Value Of The Data} In order to ensure that the time series in granger test fluctuates around the $\mathrm{Y}$-axis, the original data are de-averaged.

\section{Step3: ADF Test and KPSS Test}

This step is to check whether the sequence is stationary. If the original sequence is stationary, ADF test is used; otherwise, KPSS test is used.

\section{Step4: Calculate Rank Lag by BIC Criterion Model}

\section{Step5: Granger test}

See below for details

\section{Step6: consistency test.}

After obtaining the functional formula after the regression of the numerical points in the time series, the consistency test is used to judge whether the theoretical value and the actual value come from the same distribution.

The following is the granger causality test flow chart: 


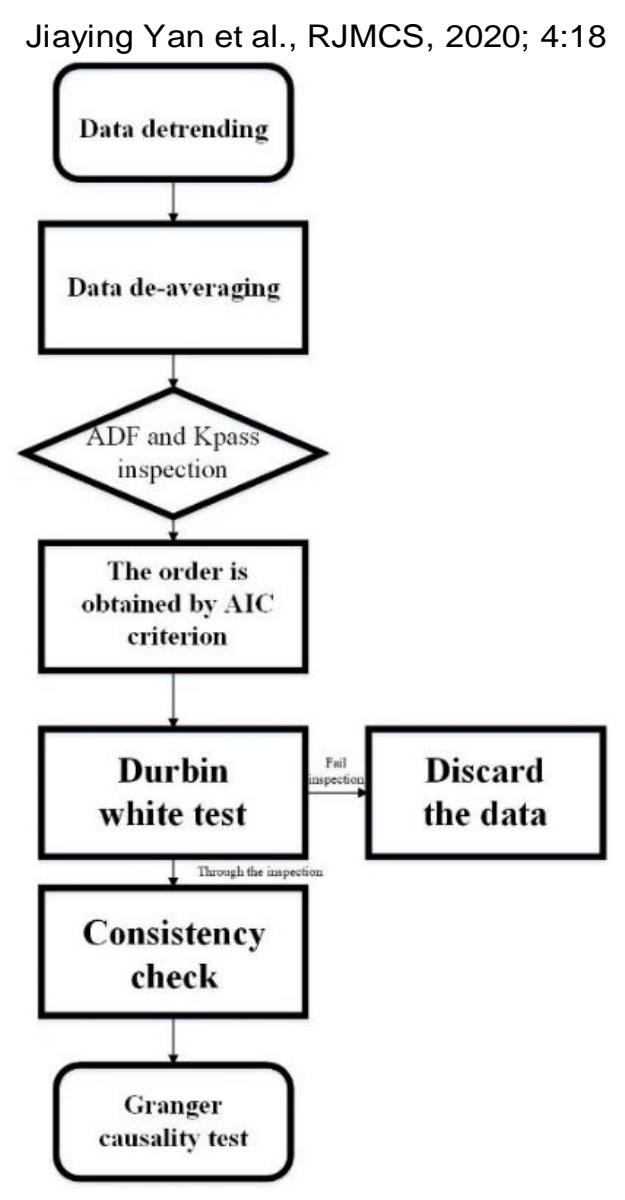

Fig 5 granger causality test flow chart

Based on the model preparation, the sequence modeling respectively established for $X_{1}$ (waste plastics imports) on $Y_{1}$ (domestic plastic products producer price index), $\mathrm{X}_{2}$ (waste paper imports) on $Y_{2}$ (paper products manufacturing producer price index), $X_{3}$ (scrap metal imports) on

$$
\begin{gathered}
Y_{\mathrm{t}}=\alpha_{0}+\sum_{i=1}^{p} \alpha_{i} Y_{t-i}+\sum_{i=1}^{q} \beta_{i} X_{t-i}+\varepsilon_{t} \\
Y_{t}=\alpha_{0}+\sum_{i=1}^{p} \alpha_{i} Y_{t-i}+\varepsilon_{t}
\end{gathered}
$$

Where, $H_{0}$ is the null hypothesis, $X 、 Y$ is the variable, $\varepsilon_{\mathrm{t}}$ is the white noise.

explanatory variable and the explained variable (2) construct $F$ statistics as follows: for each other, $\alpha, \beta$ is the coefficient of the

$$
F=\frac{\left(R S S_{\mathrm{r}}-R S S_{u}\right) / q}{R S S_{u} /(n-p-q-1)} \sim F(q, n-p-q-1)
$$

Where, $\mathrm{n}$ is the sample size. 
(3) test whether the null hypothesis " $H_{0}: X$ is the granger cause of $Y$ change" is true. If $F>$ $F_{\alpha}(q, n-p-q-1)$, then accept the null hypothesis, that is, $H_{0}: X$ is the granger cause of $Y$ change; otherwise, the null hypothesis cannot be accepted.

\section{Establishment of Nemero comprehensive pollution evaluation model}

\subsection{Model preparation}

In order to quantitatively analyze the domestic environment before and after the ban on outbound garbage, this paper collected from the national bureau of statistics the four indexes of wastewater discharge, cadmium, lead, hexavalent chromium and chemical oxygen demand from 2015 to 2018, as shown in table 1, which were used as the evaluation indexes of water pollution:

Table 1: pollutant content of wastewater from 2015 to 2018

\begin{tabular}{|c|c|c|c|c|}
\hline Year & 2015 & 2016 & 2017 & 2018 \\
\hline \multicolumn{5}{|l|}{ Hexavalent chromium } \\
\hline$\left(\times 10^{-7} \mathrm{mg} / \mathrm{L}\right)$ & 4.876647 & 3.209146 & 3.9 & 3.96 \\
\hline cadmium $\left(\times 10^{-7} \mathrm{mg} / \mathrm{L}\right)$ & 2.408073 & 2.151428 & 1.58 & 1.02 \\
\hline $\operatorname{lead}\left(\times 10^{-7} \mathrm{mg} / \mathrm{L}\right)$ & 10.21883 & 10.802 & 7.44 & 5.48 \\
\hline Chemical oxygen demand & 0.320397 & 0.3023 & 0.147 & 0.146 \\
\hline
\end{tabular}

Considering that the water quality in the whole country is above the medium level, this paper believes that the waters studied belong to class
1 water, and the standard limits of the four water quality indicators belonging to class 1 water are as shown in table 2 below:

Table 2: standard limits of pollutant content

\begin{tabular}{|c|c|c|c|c|}
\hline \multicolumn{5}{|c|}{ Waste water pollution index } \\
\hline$(m g / L)$ & Hexavalent chromium & cadmium & lead & Chemical oxygen demand \\
\hline The standard limit & 0.005 & 0.001 & 0.005 & 15 \\
\hline
\end{tabular}

\section{2 model establishment}

In order to study the impact of the ban on foreign garbage on China's environment, based on the data of several years' wastewater pollu- tion, the steps of the Nemero comprehensive pollution evaluation model are as follows:

Step1: The weights of the four monitoring indicators are calculated as follows: 


$$
a_{i}=\frac{\frac{l_{\max }}{l_{i}}}{\frac{\sum_{i=1}^{n} l_{\max }}{l_{i}}}
$$

Where, $l_{\max }$ represents the maximum standard limits for water quality under category I of the four monitoring items in each year, $l_{i}$ repre-

$$
C_{m}{ }^{\prime}=\frac{\sum_{i=1}^{n} L_{i j} \cdot a_{i}}{n}, n=1,2,3,4
$$

Where, $a_{i}$ represents the weight of the four monitoring indicators on water quality rating, $L_{i j}$ For the four monitoring indicators in the section $j$ In view of the estimation of the overall water quality of the whole country, this paper selects sents the standard values of the four monitoring indicators in all kinds of water quality.

Step2: The determination of $\mathrm{C}_{\mathrm{m}}$

$$
P_{m}{ }^{\prime}=\sqrt{\frac{C_{i \max }{ }^{2}+C_{m}{ }^{\prime}}{2}} \quad(m=1,2,3,4)
$$

Step4: Water pollution scores were calculated based on data from 2015 to 2018.

\section{Model solution and analysis}

\subsection{Economic evaluation model -- solution} and analysis of granger causality test model By the national bureau of statistics collected waste paper, scrap metal, waste plastics three foreign garbage from January 2017 to April the standard value of the four monitoring indicators belonging to the first category of water quality as $L_{i 1}, n$ Is the number of monitoring indicators.

Step3: Water pollution score calculation.

2019 imports and its manufacturing producers producer price index, using MATLAB software to solve the above model of granger causality test, under the constraint of Bayesian criteria, draw with $X_{1} Y_{1}, Y_{2}$ and $X_{2}, Y_{3}$ and $X_{3}$ regression sequence of lag value of $6,1,1$, respectively and statistic values are shown in table 3 below:

Table 3 results of granger causality test

\begin{tabular}{cccc}
\hline Null hypothesis & Order number & $\mathrm{F}$ & $\mathrm{P}$ \\
\hline $\begin{array}{c}\text { The ban on waste paper caused an increase in the pro- } \\
\text { ducer price index of domestic paper industry }\end{array}$ & 6 & 1.2265 & 0.2806 \\
$\begin{array}{c}\text { The ban on scrap metal caused an increase in the pro- } \\
\text { ducer price index of domestic metal products }\end{array}$ & 1 & 4.14 & 0.0724 \\
The ban on waste plastics caused an increase in the & 1 & 2.75 & 0.1093 \\
\hline
\end{tabular}


From the $\mathrm{P}$ values obtained from the three original hypotheses in the above table, it can be seen that under the condition of $5 \%$ confidence, all three original hypotheses are accepted, it can be considered that the foreign waste ban does cause an increase in the corresponding manufacturing factory price index, that This has an impact on the Chinese economy, and a reduction in the amount of imported waste will increase the corresponding ex-factory price.

\subsection{Environmental assessment model -- so- lution and analysis of nemerow comprehen- sive pollution assessment model}

The quality and pollution levels of surface water found online are shown in table 4:

Table 4: classification of surface water quality

\begin{tabular}{cccccc}
\hline score & $\mathrm{P}<0.62$ & $0.62<\mathrm{p}<0.73$ & $0.73<\mathrm{p}<1$ & $1<\mathrm{p}<7.28$ & $7.28<\mathrm{p}<11$ \\
\hline $\begin{array}{c}\text { Pollution level descrip- } \\
\text { tion }\end{array}$ & clean & cleaner & Light pollution & $\begin{array}{c}\text { Moderate pollu- } \\
\text { tion }\end{array}$ & Serious pollution \\
\hline
\end{tabular}

The four indexes of wastewater discharge, cadmium, lead, Hexavalent chromium and chemical oxygen demand in water from 2015 to 2018 were brought into the above nemerow compre- hensive pollution evaluation model to obtain the water pollution scores in the four years as shown in table 5:

Table 5: water pollution scores from 2015 to 2018

\begin{tabular}{ccccc}
\hline Year & 2015 & 2016 & 2017 & 2018 \\
\hline Scores for water pollution & 0.677554 & 0.659676 & 0.706233 & 0.680287 \\
\hline
\end{tabular}

Four years of water quality pollution score compared to the surface water quality classification, can know before trash ban in 2017, the pollutants in the waste water to China's water pollution situation bad year by year, in July 2017 ban on waste paper, waste plastics and scrap metal, water pollution situation improves, shows that junk ban will improve China's environment. The nemero score for water quality in 2018 was 0.026 lower than in 2017.

\section{8. Model evaluation}

Granger causality test model, which belongs to the economic model, can explain the impact of foreign garbage ban on China's economy more accurately. Because the problem data is difficult to collect, this paper only makes model solutions to the collected data, which cannot fully reflect the environmental and economic impact of the ban on foreign garbage on China and the world, nor can it accurately reflect the economic and environmental impact of the garbage classification policy on China in the next five years. 


\section{Model generalization and improvement}

\subsection{Model improvement}

(1) there are many factors influencing the environmental and economic impacts of the ban on foreign garbage in China and the world. Due to the difficulty in data collection, this paper only considers single or bivariate variables, which cannot accurately reflect the impact of the ban on foreign garbage and garbage classification. It should be analyzed by integrating various factors.

(2) for the reflection of the impact, intuitive indicators such as concentration of environmental pollutants should be selected.

\subsection{Model generalization}

Granger causality test (granger causality test) is a method developed by economists to analyze granger causality among variables. The test was developed by Clive granger, winner of the Nobel Prize in economics in 2003, to analyze the granger causality between economic variables. He defines granger causality as "the variance of the best least-squares prediction that depends on using all the information at some point in the past." The method can also be applied to the causality test between other economic variables.

\section{Conclusion}

In this paper, the granger causality test model and nemero comprehensive pollution model are proposed to analyze the economic and environmental impacts of the ban on foreign garbage on China. The solution of the model shows that the lower the quantity of foreign garbage, the higher the ex-factory price of the corresponding products. Moreover, the promulgation of the ban on foreign garbage has improved China's environment to a certain extent. This model can quantitatively analyze the impact of a policy on a country and the impact of other policies on a country Thus, using these models well, then the analysis of the impact of other policies on countries is instructive.

\section{References}

1. Yongfu Cao. Review of Granger's causality test [J] Quantitative and Technical Economics Research, 2006 (01): 155-160.

2. "Foreign Waste" Ban, How Should China's Recycling Industry Go Forward?[J]. Economic Analysis of China Petroleum and Chemical Industry, 2019 (04): 1.

3. Xuechen Wang. One year ban on "foreign garbage" China's decision affects global solid waste treatment system [J]. Resources Recycling, 2018 (09): 12-15.

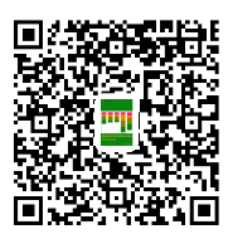

